\title{
The role of immunohistochemistry in the Muir-Torre Syndrome*
}

\author{
Cláudia Marina Puga Barbosa Oliveira ${ }^{1}$ \\ Maiko Ramacos Maia ${ }^{1}$ \\ Fábio Francesconi do Valle ${ }^{1}$
}

Jullyene Gomes de Campos ${ }^{1}$

Larissa Eva dos Santos Lobo ${ }^{1}$

DOI: http:/ / dx.doi.org/10.1590/abd1806-4841.20153406

\begin{abstract}
A bstract: Muir-Torre Syndrome is defined by the coexistence of sebaceous skin tumors and internal malignancies. Mutations in the DNA mismatch repair genes are found in the inherited form of the disease, resulting in the absence of crucial enzymes involved with DNA replication process. This case describes a patient with sebaceous adenoma and colorectal carcinoma, meeting the criteria for Muir-Torre Syndrome. The immunohistochemical analysis of the skin lesion was an important tool to confirm the diagnosis, as it revealed nuclear negativity for MSH2 and MSH6.
\end{abstract}

Keywords: Adenoma; Colorectal Neoplasms; DNA Repair; Muir-Torre Syndrome

\section{INTRODUCTION}

Described by Muir et al and Torre, Muir-Torre Syndrome (MTS) is a rare autosomal dominant condition with a high degree of penetrance. ${ }^{1,2}$ In 1995, diagnostic criteria for the syndrome were proposed by Schwartz and Torre, which included the presence of a sebaceous tumor (sebaceous adenoma, sebaceous carcinoma or sebaceoma) and at least one visceral malignancy. ${ }^{3}$

Currently, it is believed that there are two types of MTS. The most common form is a variant of Hereditary Nonpolyposis Colorectal Cancer or Lynch Syndrome, associated with germline mutations in DNA repair genes encoders of proteins $\mathrm{MutL} H$ omolog 1 (M LH 1) and M utS Homolog 2 (M SH 2). Recently, mutations in genes of proteins $\mathrm{M}$ utS Homolog 6 (M SH 6) and Postmeiotic Segregation Increased 2 (PM S2) were also implicated. The other spectrum of the disease, however, has no correlation with family history and seems to involve other genes than the DNA repairing ones. ${ }^{4,5}$

In this article, the authors report the case of a male patient with multiple sebaceous tumors and history of colorectal carcinoma. The immunohistochemical study of the cutaneous neoplasm was used to corroborate the diagnosis of Muir-Torre Syndrome, revealing the expected negativity for DNA repair enzymes.

\section{CASE REPORT}

Male patient, 41 years old, presented at the Dermatology service complaining about the onset of multiple yellowish papules with central umbilication located on the face (Figures 1 and 2). The anatomopathological examination was conclusive for sebaceous adenoma (Figure 3). An immunohistochemical study was performed through a standard technique, with parts (sugestão: tissue pieces) in paraffin blocks and histological sections incubated with a panel of monoclonal antibodies. A polymer-based detection system was used. The antibodies used were repair enzymes M SH 2, M SH 6 and M LH 1, with nuclear negativity occurring for $\mathrm{MSH} 2$ and $\mathrm{MSH} 6$ and inconclusive M LH 1 search (Figures 4 and 5).

Received on 27.01.2014

Approved by the Advisory Board and accepted for publication on 06.03.2014

Work performed at Hospital Universitário Getúlio Vargas - Universidade Federal do Amazonas (HUGV-UFAM) and Fundação Centro de Controle de Oncologia do Estado do Amazonas - Manaus (AM), Brazil.

Financial Support: None.

Conflict of Interest: None.

1 Universidade Federal do Amazonas (UFAM) - Manaus (AM), Brazil.

(C)2015 by Anais Brasileiros de Dermatologia 


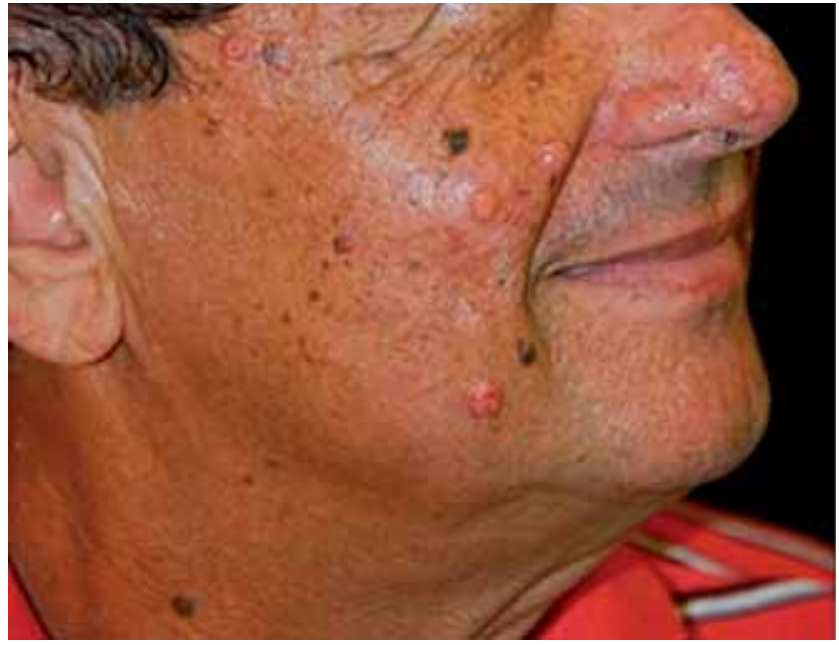

Figure 1: Sebaceous adenomas on the face of patient with Muir-Torre Syndrome

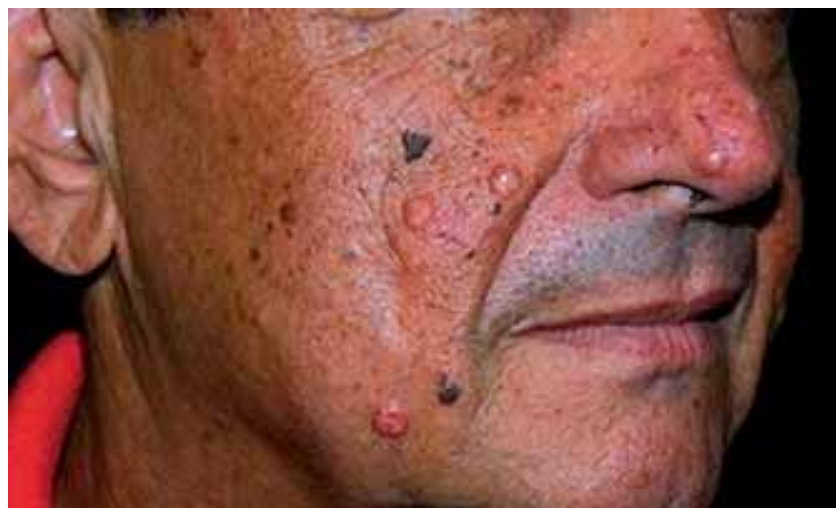

Figure 2: Detail of papular lesions on the face

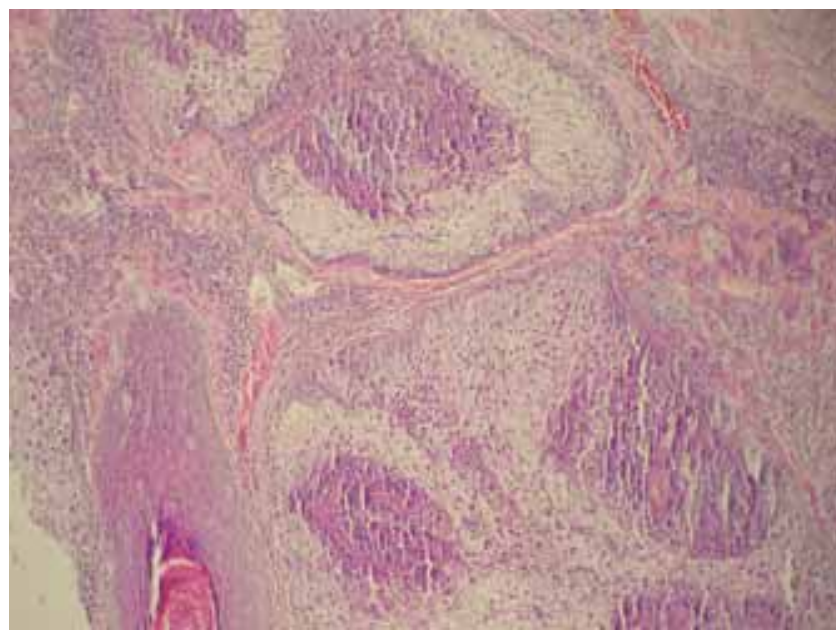

FIGURE 3: A natomopathological examination: sebaceous adenoma

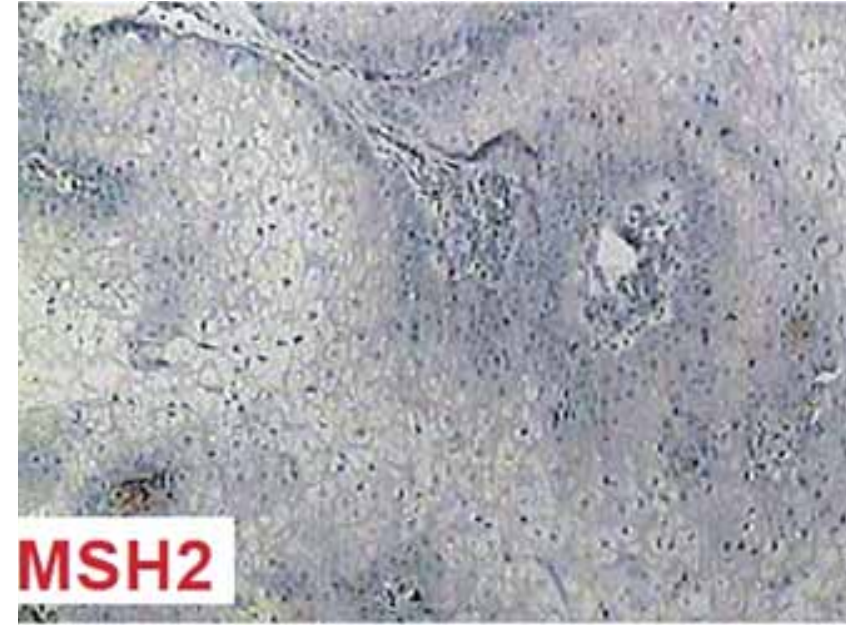

Figure 4: Immunohistochemical examination: sebaceous adenoma revealing nuclear negativity for repair enzyme MSH 2

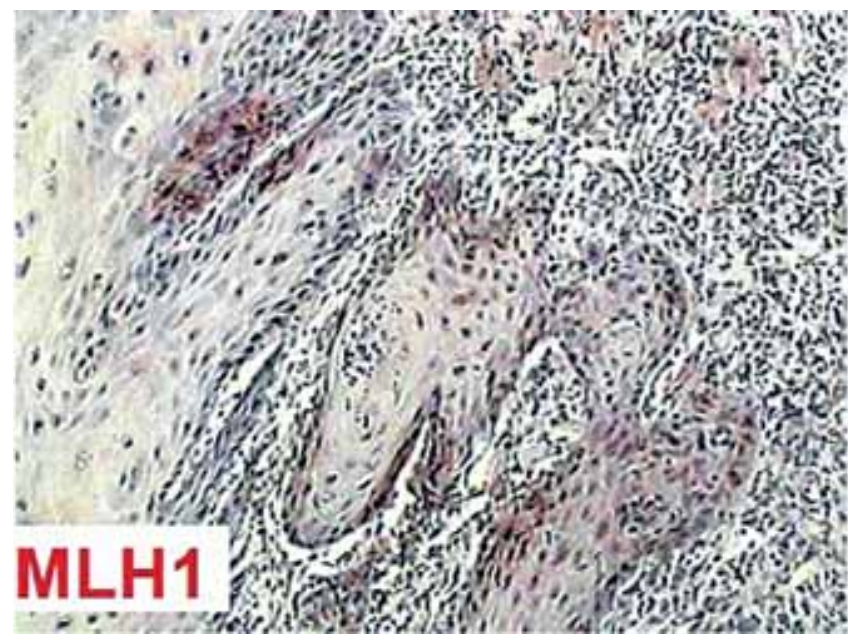

Figure 5: Immunohistochemical examination: sebaceous adenoma in a positive control patient showing preserved nuclear reactivity for repair enzyme MLH 1

\section{DISAUSSION}

The most frequent MTS subtype is the phenotypic spectrum of Lynch syndrome, in which mutations of DNA repair genes can be detected.

The DNA repairing system is critically important to maintain genome stability during DNA replication. Failure in this process results in mutation of genetic material and microsatel lite instability. For example, the loss of expression of the protein coded by gene M SH 2 leads to the accumulation of replication errors, which ultimately is related to tumor susceptibility. ${ }^{6,7}$ 
MTS mutations predispose for the onset of $\mathrm{cu}$ taneous tumors of sebaceous origin. Notwithstanding, the mechanism through which the loss of repairing proteins and microsatellite instability result in this type of tumor has not yet been elucidated. ${ }^{8}$

In general, sebaceous tumors are rare in the population, and for this reason their onset represents an important marker for investigation of the syndrome. ${ }^{9}$ The most frequently found cutaneous neoplasms are sebaceous adenoma, sebaceous carcinoma and sebaceoma, which are usually subsequent to the diagnosis of visceral carcinoma in $56 \%$ of the cases. Keratoacanthomas and non-melanoma skin carcinomas are also described with sebaceous differentiation in the carriers of the disease. ${ }^{4}$

As to visceral neoplasms, colorectal carcinomas account for $51 \%$ of the cases. Malignancies of the genitourinary system, breast, lungs, parotid gland, upper gastrointestinal tract, larynx and blood may be present, although rarely. The follow-up of these patients is comprised of colonoscopy every 3-5 years, starting at 25-30 years of age, cystoscopy and intravenous pyelogram at regular intervals, computed tomography of the abdomen and pelvis every 2-5 years, yearly mammogram and endometrial biopsy every 3-5 years in women over 50 years of age ${ }^{4,10}$

The diagnosis of MTS is eminently clinical, corroborated by exams such as immunohistochemistry and molecular analysis. Since the first publications reporting the detection of repairing enzymes through the immunohistochemical method, loss of M LH 1 and M SH 2 expression was observed in colorectal carcinomas with microsatellite instability. Despite the microsatellite instability detected through PCR remaining as standard methodology, the employment of immunohistochemistry in literature has expanded. ${ }^{8,10}$

Analogous to this, the immunohistochemical study with antibodies against repair proteins $\mathrm{MSH} 2$, M LH 1 and M SH 6 is currently the accepted method for evaluation of the function of these proteins in sebaceous neoplasms. The lack of nuclear immunoreactivity in tumor cells suggests MTS and has shown good correlation of this finding with microsatellite instability when compared to gold-standard tests. ${ }^{8}$

Mathiak et al emphasize that the repair enzymes express themselves properly in sporadic cases of sebaceous carcinoma, which reinforces even further the role of immunohistochemistry in the characterization of MTS. ${ }^{6}$

Therefore, immunohistochemistry presents applicability in clinical practice as an element of identification of neoplasms, which carry deficiency in the activity of repair enzymes and phenotype of microsatellite instability. It is outstanding for MTS confirmation, as it is more accessible and less costly than molecular analysis, allied to its high positive predictive value. ${ }^{6}$

When suspicious of MTS, the dermatologist may proceed with an immunohistochemical study of sebaceous tumors, if molecular analysis is not available to confirm the disease, thus allowing secondary prevention of visceral tumors. In our case, the absence of repair enzymes M SH 2 and M SH 6 in the immunohistochemical study reiterated the diagnosis of MTS and triggered a series of propedeutic actions, aiming for early diagnosis of morbidities and genetic counseling.]

\section{REFERENCES}

1. Muir EG, Bell AJ, Barlow KA. Multiple primary carcinomata of the colon, duodenum, and larynx associated with keratoacanthomata of the face. Br J Surg. 1967;54:191-5.

2. Torre D. Multiple sebaceous tumors. Arch Dermatol. 1968;98:549-51.

3. Schwartz RA, Torre DP. The Muir-Torre syndrome: a 25-year retrospect. J Am Acad Dermatol. 1995;33:90-104.

4. Ponti G, Ponz de Leon M. Review: Muir-Torre syndrome. Lancet Oncol. 2005;6:980-7.

5. Tavakkol Z, Keller JJ, Furmanczyk PS, Bennett RL, Chien AJ. Germline mutation in MSH6 associated with multiple malignant neoplasms in a patient with Muir-Torre syndrome. J Clin Oncol. 2012;30:e195-8.

6. Mathiak M, Rütten A, Mangold E, Fischer HP, Ruzicka T, Friedl W, et al. Loss of DNA mismatch repair proteins in skin tumors from patients with Muir-Torre syndrome and MSH2 e MLH1 germline mutations: Establishment of immunohistochemical analysis as a screening test. Am J Surg Pathol. 2002;26:338-43.

7. Lee BA, Yu L, Ma L, Lind AC, Lu D. Sebaceous neoplasms with mismatch repair protein expressions and the frequency of co-existing visceral tumors. J Am Acad Dermatol. 2012;67:1228-34.

8. Shalin SC, Lyle S, Calonje E, Lazar AJ. Sebaceous neoplasia and the Muir-Torre syndrome: important connections with clinical implications. Histopathology. 2010;56:133-47.

9. Tsalis K, Blouhos K, Vasiliadis K, Tsachalis T, Angelopoulos S, Betsis D. Sebaceous gland tumors and internal malignancy in the context of Muir-Torre syndrome. A case report and review of the literature. World J Surg Oncol. 2006;4:8.

10. Ko CJ. Muir-Torre syndrome: facts and controversies. Clin Dermatol. 2010;28:3249

\begin{tabular}{l}
\hline M AILIN G ADDRESS: \\
Cláudia M arina Puga Barbosa Oliveira \\
Rua A, 44 - Conjunto A ristocrático \\
Chapada \\
$69050-130$ - M anaus - A M \\
Brazil \\
E-mail: claudiamarinapuga@hotmail.com
\end{tabular}

H ow to citethis article:Oliveira CMPB, Campos JC, Maia MR, Lobo LES, ValleFF. The role of immunohistochemistry in the Muir-Torre Syndrome. An Bras Dermatol. 2015;90 (3 Suppl 1):168-70. 